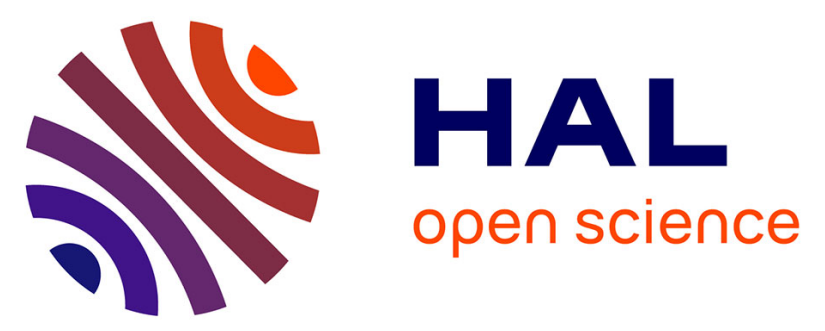

\title{
Treatment efficacy of DNA lipid nanocapsules and DNA multimodular systems after systemic administration in a human glioma model
}

Stephanie David, Tristan Montier, Nathalie Carmoy, Pauline Resnier, Anne Clavreul, M. Mevel, Bruno Pitard, Jean-Pierre Benoit, Catherine

Passirani-Malleret

\section{To cite this version:}

Stephanie David, Tristan Montier, Nathalie Carmoy, Pauline Resnier, Anne Clavreul, et al.. Treatment efficacy of DNA lipid nanocapsules and DNA multimodular systems after systemic administration in a human glioma model. The Journal of Gene Medicine, 2012, 14 (12), pp.769-775. 10.1002/jgm.2683 . hal-03165446

\author{
HAL Id: hal-03165446 \\ https://univ-angers.hal.science/hal-03165446
}

Submitted on 10 Mar 2021

HAL is a multi-disciplinary open access archive for the deposit and dissemination of scientific research documents, whether they are published or not. The documents may come from teaching and research institutions in France or abroad, or from public or private research centers.
L'archive ouverte pluridisciplinaire HAL, est destinée au dépôt et à la diffusion de documents scientifiques de niveau recherche, publiés ou non, émanant des établissements d'enseignement et de recherche français ou étrangers, des laboratoires publics ou privés. 


\section{Treatment efficacy of DNA lipid nanocapsules and DNA multimodular systems after systemic administration in a human glioma model}

\author{
Stephanie David ${ }^{1,2,3}$ \\ Tristan Montier $5,6,7$ \\ Nathalie Carmoy 5,6 \\ Pauline Resnier ${ }^{1,2}$ \\ Anne Clavreul ${ }^{1,2,8}$ \\ Mathieu Mével ${ }^{3}$ \\ Bruno Pitard ${ }^{3,4}$ \\ Jean-Pierre Benoit ${ }^{1,2}$ \\ Catherine Passirani ${ }^{1,2 *}$ \\ ${ }^{1}$ LUNAM Université - Equipe MINT: \\ micro et nanomédecines \\ biomimétiques, IBS-CHU, 4 rue \\ Larrey, 49933 Angers Cedex 9, France \\ ${ }^{2}$ INSERM - U1066, Université \\ d'Angers, IBS-CHU, 4 rue Larrey, \\ 49933 Angers Cedex 9, France \\ ${ }^{3}$ INSERM - UMR 1078, Université de \\ Nantes, IRT-UN, 8 Quai Moncousu, BP \\ 70721, 44007 Nantes cedex 1, France \\ ${ }^{4}$ IN-CELL-ART, 1 place Alexis \\ Ricordeau, F-44000 Nantes, France \\ ${ }^{5}$ NSERM U1078, IFR 148 ScInBIoS, \\ Université de Bretagne Occidentale, \\ Faculté de médecine, 22 rue Camille \\ Desmoulins, CS 93837, 29238 Brest \\ cedex 3, France \\ ${ }^{6}$ IBiSA « SynNanoVect » platform; IFR \\ 148 ScInBIoS ; Université de Bretagne \\ Occidentale, Faculté de médecine, 22 \\ rue Camille Desmoulins, CS 93837 - \\ 29238 Brest cedex 3, France \\ ${ }^{7}$ DUMG ; Université de Bretagne \\ Occidentale, Faculté de médecine, 22 \\ rue Camille Desmoulins - CS 93837 - \\ 29238 Brest cedex 3 - France; CHRU \\ de Brest, 5 avenue du Marechal Foch, \\ 29200 Brest, France \\ ${ }^{8}$ Département de Neurochirurgie - \\ CHU d'Angers, 4 rue Larrey, 49933 \\ Angers, France \\ *Correspondence to: C. Passirani, \\ Inserm U1066, IBS-CHU, 4 rue Larrey, \\ 49933 Angers Cedex 9, France. \\ E-mail: catherine.passirani@ \\ univ-angers.fr
}

Received: 23 February 2012

Revised: 15 July 2012

Accepted: 5 November 2012

\begin{abstract}
Background We previously developed different types of DNA nanocarriers for systemic administration. Recently, the biodistribution profiles of these intravenously administered nanocarriers, DNA lipid nanocapsules (LNCs) and different multimodular systems (MMS), were analysed in healthy mice using in vivo biofluorescence imaging.
\end{abstract}

Methods In the present study, the experiments were performed in an ectopic human U87MG glioma model in nude mice. First, the biodistribution profiles of intravenously administered multimodular systems delivering a plasmid DNA with a luciferase cassette were analysed using in vivo biofluorescence imaging. Afterwards, a systemic treatment with two long circulating DNA nanocarriers, poly(ethylene glycol) (PEG) DNA LNCs and galactose (GAL) DNA MMS dioleylamin-succinyl paromomycin (DOSP) was performed on this glioma model using a plasmid encoding the herpes simplex virus thymidine kinase (HSV-tk) and subsequent ganciclovir (GCV) treatment.

Results The biodistribution profiles of the different DNA nanocarriers on this glioma model were similar to those observed on healthy animals and varied in function of their cationic lipid composition and their surface characteristics. Furthermore, PEG DNA LNCs and GAL DNA MMS DOSP showed a specific accumulation and some luciferase expression in the tumour tissue. The systemic treatment using the HSV-tk/GCV approach showed a tumour growth reduction compared to the nontreated mice cohort.

Conclusions These results are in good accordance with those obtained previously with PEG DNA LNCs in a human melanoma mouse model and highlight the potential use of GAL DNA MMS DOSP and PEG DNA LNCs as future therapeutics in glioma and other cancers. Copyright (C) 2012 John Wiley \& Sons, Ltd.

Keywords gene therapy; GDEPT; in vivo biofluorescene imaging; GAL DNA MMS DOSP; PEG DNA LNCs; systemic administration

\section{Introduction}

Malignant gliomas are highly aggressive primary adult brain tumours with poor prognosis [1]. The most aggressive form is the glioblastoma multiform, characterized by its diffuse invasion of the surrounding normal tissue and its recurrence after all forms of therapy [2]. The standard treatment is maximal safe surgical resection followed by radiotherapy and temozolomide chemotherapy which improves the median overall survival for up to 5 years in some cases [3]. 
However, most patients will still die of their disease and the development of new improved treatments should be given priority.

One option is the combination of herpes simplex virus thymidine kinase (HSV-tk) with the prodrug ganciclovir (GCV), known as gene-directed enzyme prodrug therapy (GDEPT) $[4,5]$. This therapy was already shown to be efficient on patients with operable primary or recurrent malignant glioma. An increase in patient survival time of 71 weeks compared to 39 weeks in the control group could be attained by local HSV-tk administration after tumour resection using adenovirus [6]. The major drawbacks of using viruses as gene delivery vectors are their potential risk, as associated with replication-competent viruses, immunogenicity and a high cost [7-9]. For this reason, nonviral delivery agents have been developed that do not present these drawbacks and, instead, have the advantage of being able to carry large inserts and to be easily modifiable for active or passive targeting [10-12].

Previously, different nonviral DNA nanocarriers were developed in our laboratories. DNA lipid nanocapsules (LNCs), encapsulating DNA lipoplexes in their liquid lipid core, have proved their transfection efficiency in vitro. Poly (ethylene glycol) (PEG) DNA LNCs (coated DNA LNCs with DSPE-PEG ${ }_{2000}$ ) demonstrated their transfection efficiency in vivo using a luciferase-coding plasmid on a tumour model (HEKß3 in nude mice) [13-15]. DNA multimodular systems (MMS) containing the cationic lipid bis(guanidinium)-tris (2-aminoethyl)amine-cholesterol (BGTC) (DNA MMS BGTC), were developed by Letrou-Bonneval et al. [16] and demonstrated a specific transfection in primary hepatocytes after a coating with galactose (GAL) (GAL DNA MMS BGTC). Previously, DNA MMS based on the cationic lipid dioleylamin-succinyl paromomycin (DOSP) in the presence and absence of galactose (GAL DNA MMS DOSP and DNA MMS DOSP) were developed and the biodistribution profiles of all these different DNA nanocarriers after systemic administration on healthy mice were analysed, revealing an accumulation in the liver for DNA MMS BGTC and GAL DNA MMS and a prolonged circulation time for DNA MMS DOSP [17]. Both formulations were based on lipoplexes (complexes of DNA with a cationic lipid) and had a dual core-shell (LNCs) or core-corona structure (MMS). Our strategy was to use different DNA nanocarriers that previously showed interesting characteristics [14-18] to administer HSV-tk via systemic administration in an ectopic human U87MG glioma model in nude mice followed by GCV treatment. First, the biodistribution of the systemically administered DNA nanocarriers, encapsulating a fluorescent dye and a luciferase-coding plasmid DNA, was followed via non-invasive in vivo biofluorescence imaging (BFI) and luciferase expression in different organs, and tumour tissue was assessed. Afterwards, DNA nanocarriers showing the best tumour targeting were chosen to administer the HSV-tk/GCV treatment in the human glioma model and to evaluate its efficiency in tumour growth reduction.

\section{Materials and methods}

\section{Preparation of nanocarriers}

Plasmids, lipids for liposome preparation and steric stabilisers The pGWIZ ${ }^{\mathrm{TM}}$-luciferase DNA plasmid (Gene Therapy systems, Inc., San Diego, CA, USA) was used for DNA nanocarrier characterisation, biodistribution analysis and luciferase quantification and the pORF-TK- CpG DNA plasmid (InvivoGen, Toulouse, France) was used for treatment using the GDEPT. The cationic lipids DOSP (synthesis described previously [19]) and BGTC (synthesis described previously [20]) were used for DNA MMS preparation and the cationic lipid DOTAP (1,2-dioleyl-3-trimethylammoniumpropane) (Avanti Polar Lipids Inc., Alabaster, AL, USA) was used for DNA LNC preparation. All lipids were combined with the neutral lipid DOPE (1,2-dioleyl-sn-glycero-3-phosphoethanolamine) (Avanti Polar Lipids Inc.). The polymer F108 [80\% poly(ethylene oxide), molecular weight $=14600$ ] was generously provided by BASF (Ludwigshafen, Germany) and the galactosylated form was synthesised as described previously [16].

\section{Preparation of liposomes}

Liposomes were composed of a cationic lipid (DOSP, BGTC or DOTAP) in addition to the neutral helper lipid DOPE in the ratio $1: 1(\mathrm{M} / \mathrm{M}), 3: 2(\mathrm{M} / \mathrm{M})$ or $1: 1(\mathrm{M} / \mathrm{M})$, respectively. The different lipids solubilised in chloroform were weighted to obtain a final concentration of $20 \mathrm{mM}$ of cationic lipid charge, considering the number of lipid charges per molecule ( 4 for DOSP, 2 for BGTC and 1 for DOTAP). Next, chloroform was evaporated under vacuum to obtain a homogen lipid film, which was hydrated with deionised water overnight at $4^{\circ} \mathrm{C}$. The next day, liposomes were sonicated and their size measured before use.

\section{Preparation of DNA multimodular systems}

To prepare MMS, equal volumes of a mixture composed of the steric stabilizer (F108 or F108-gal), liposomes (BGTC/ DOPE or DOSP/DOPE) and water were added to a mixture composed of plasmid DNA, $\mathrm{NaCl}$ and water to obtain final concentrations of $0.25 \mathrm{~g} / \mathrm{l} \mathrm{DNA}$ and $0.15 \mathrm{M} \mathrm{NaCl}$, with a charge ratio $(+/-)$ of 2 and a polymer/DNA ratio of $300(\mathrm{w} / \mathrm{w})$. MMS were incubated for $20 \mathrm{~min}$ at room temperature before use.

\section{Preparation of (PEG) DNA lipid nanocapsules}

DNA LNCs were prepared as described previously [13]. Briefly, LNCs were composed of 9.9\% (w/w) lipophilic Labrafac $^{\circledR}$ WL 1349 (Gatefossé S.A., Saint-Priest, France), $3.9 \%(\mathrm{w} / \mathrm{w})$ oleic Plurol ${ }^{\circledR}$ (polyglyceryl-6 dioleate), which was kindly provided by Gatefossé SA (Saint-Priest, France), 1.4\% (w/w) NaCl (Prolabo, Fontenay-sous-Bois, France), 78.9\% (w/w) water (obtained from a Milli-Qplus ${ }^{\circledR}$ system; Millipore, Paris, France) and 5.9\% (w/w) Solutol ${ }^{\circledR}$ HS-15 (BASF). Lipoplexes containing the plasmid coding for luciferase or for HSV-tk and DOTAP/DOPE liposomes in a charge ratio (+/-) of 5 were added instead of the formulation water. For in vivo BFI, the near-infrared 
fluorescent dye; 1,1'-dioctadecyl-3,3,3',3'-tetramethylindodicarbocyanine perchlorate $(\mathrm{DiD}$, emission $=644 \mathrm{~nm}$; excitation $=665 \mathrm{~nm}$ ) (Invitrogen, Cergy-Pontoise, France) was mixed with Labrafac ${ }^{\circledR}$ as described previously [21]. The formulation process was based on the phase inversion of a microemulsion [22]. Briefly, after mixing all the components, temperature cycles around the phase-inversion-temperature were performed under magnetic stirring. Next, cold water (in the ratio 1:1.96) was added to dilute the microemulsion and to form DNA LNCs.

DNA LNCs were then passed on PD10 Sephadex columns (Amersham Biosciences Europe, Orsay, France), ultrafiltrated with MilliporeAmicon ${ }^{\circledR}$ Ultra-15 centrifugal filter devices (Millipore, St Quentin-Yvelines, France) and the salt and LNC concentrations were readjusted afterwards to obtain a physiological concentration of $\mathrm{NaCl}$ (150 mM) and the initial concentration of LNCs (152 g/l).

Half of these purified DNA LNCs were then mixed with; 1,2-distearoyl-sn-glycero-3-phosphoethanolamine- $N$ [methoxy (polyethyleneglycol)-2000] (DSPE-mPEG 2000 ) (mean molecular weight $=2805 \mathrm{~g} / \mathrm{mol}$ ) (Avanti Polar Lipids, Inc.), incubated for $4 \mathrm{~h}$ at $30^{\circ} \mathrm{C}$ and vortexed every 15 min to obtain PEG DNA LNCs with a final polymer concentration of $10 \mathrm{mM}$.

\section{Physicochemical characterisation of DNA nanocarriers}

Coated and noncoated DNA LNCs were diluted with deionised water at a ratio of 1:100 and the different DNA MMS with $0.15 \mathrm{M} \mathrm{NaCl}$ at a ratio of 4:100 before measuring their size and zeta potential with a Malvern Zetasizer ${ }^{\circledR}$ (Nano Series ZS, Malvern Instruments S.A., Malvern, UK) at $25^{\circ} \mathrm{C}$. All measurements were performed in triplicate and with similar conductivity values.

\section{In vivo experiments}

Ectopic human glioma model in nude mice

Six- to 9-week-old female, nude SWISS mice (Charles River, L'Arbresle, France) were housed and maintained at the University animal facility. They were processed in accordance with the Laboratory Animal Care Guidelines (NIH Publication 85-23, revised 1985) and with the agreement of the regional veterinary services (authorisation FR; 29-024).

Tumour-bearing mice were prepared by injecting subcutaneously a suspension of $1 \times 10^{6}$ U87MG glioblastomaastrocytoma cells ( ${ }^{\circ} \mathrm{HTB}-14-\mathrm{ATCC}$ ) in $100 \mu \mathrm{l}$ of Hanks buffered salt solution into the right flank of athymic nude SWISS mice (6-week-old females, 20-24 g). Three weeks after tumour implantation, $150 \mu \mathrm{l}$ of DNA LNCs or PEG DNA LNCs or $200 \mu \mathrm{l}$ of DNA MMS was administered by intravenous injection into the tail vein of the mice. Animals were sacrificed $24 \mathrm{~h}$ after intravenous injection.
In vivo biofluorescence imaging (BFI)

Non-invasive BFI was performed as described previously [15] at 1, 3, 5 and $24 \mathrm{~h}$ post-injection, using the BFI system of NightOWL II (Berthold Technologies, Germany). Briefly, WinLight 32 software (Berthold Technologies, Germany) was used, the $590 \mathrm{~nm}$ excitation and $655 \mathrm{~nm}$ emission filters were selected, and each mouse was anaesthetised with isofluran during the acquisition ( $3 \mathrm{~s}$ for one fluorescent acquisition). The fluorescent signal was then overlaid on an image of each mouse.

\section{Luciferase quantification}

Organs from the sacrificed animals were placed in tubes with PLB 1x (Passive Lysis Buffer; Promega, Madison, WI, USA) and shaken with the gentleMACS Dissociator (Miltenyi Biotec, Bergisch Gladbach, Germany). Tubes were centrifuged at $1150 \mathrm{~g}$ for $10 \mathrm{~min}$ at $4^{\circ} \mathrm{C}$ and the upper phase transferred into Eppendorf tubes. After another centrifugation of $20000 \mathrm{~g}$ for $10 \mathrm{~min}$ at $4^{\circ} \mathrm{C}, 25 \mu \mathrm{l}$ of the upper phase was placed in triplicate in a white 96-well plate and quantification with luciferin reagent (Promega) was performed with the MLX luminometer plate reader (Dynex, Guyancourt, France).

\section{Treatment efficacy of DNA nanocarriers}

Nude Swiss mice bearing subcutaneous glioma cells in the right flank were prepared as described above. Animals were weighted and tumour dimensions were measured regularly. Tumour volume was calculated using the formula: $\pi / 6 \times$ length $^{2} \times$ width. Mice were distributed in different groups as a function of their tumour volume to obtain randomized homogen groups with a tumour volume of $330 \pm 90 \mathrm{~mm}^{3}$ at the beginning of the treatment. Mice received one intravenous injection in the tail vein of $150 \mu \mathrm{l}$ of PEG DNA LNCs or $200 \mu \mathrm{l}$ of GAL DNA MMS DOSP, encapsulating a plasmid encoding HSV-tk followed by subsequent treatment twice a day for 4 days with $150 \mu \mathrm{l}$ intraperitoneal Ganciclovir $(10 \mathrm{mg} / \mathrm{ml}$; InvivoGen, Toulouse, France), corresponding to $65 \mathrm{mg} / \mathrm{kg}$. Control mice received no treatment, GCV alone, LNCs without DNA alone or DNA nanocarriers without GCV treatment. Mice were sacrificed at day 11 after the beginning of the treatment.

The statistical significance of various vector and treatment combinations was analysed by Student's $t$-test $(n<30)$. $p<0.05$ (two-tailed) was considered statistically significant.

\section{Results}

\section{DNA nanocarrier presentation}

In the present study, six different DNA nanocarriers, previously developed in our laboratories, were used; two types of LNCs encapsulating a plasmid DNA either without surface modification (DNA LNCs) or with a surface coating consisting of DSPE-PEG 2000 (PEG DNA LNCs) and four types of MMS using either the cationic lipid BGTC (DNA MMS BGTC, GAL DNA MMS BGTC) 
or DOSP (DNA MMS DOSP, GAL DNA MMS DOSP) in the presence or absence of the ligand GAL. The physicochemical properties of these DNA nanocarriers are presented in Table 1.

\section{In vivo fluorescence imaging of DNA nanocarriers}

To analyse the biodistribution profiles using non-invasive in vivo BFI (Figure 1), a fluorescent dye, DiD, was encapsulated in the different DNA nanocarriers. Afterwards, these fluorescent DNA nanocarriers were administered via systemic administration on a glioma model consisting of human U87MG cells implanted in the right flank of nude mice. The biodistribution of DNA LNCs, showing a broad distribution $1 \mathrm{~h}$ after administration and rapid elimination afterwards, and PEG DNA LNCs, showing a prolonged circulation time compared to DNA LNC with a tumour accumulation for both LNC types, was already reported by Morille et al. [23] in the same model. DNA MMS containing the cationic lipid BGTC accumulated preferentially in the liver, as indicated by a fluorescence signal persisting during the whole observation period in this organ with both types of DNA MMS BGTC. DNA MMS containing the cationic lipid DOSP had an augmented circulation time comparable to that for PEG DNA LNCs, as demonstrated by an intense fluorescence signal in the whole body along the observation period.

\section{Quantification of luciferase expression in different organs}

Twenty-four hours after administration of the six different DNA nanocarriers, encapsulating a luciferase-coding plasmid DNA, the animals were sacrificed and luciferase expression was quantified in different organs and tissues. In the kidney, heart and lungs, no significant luciferase expression could be detected for all DNA MMS and PEG DNA LNCs and only low luciferase expression for DNA LNCs (data not shown). For DNA MMS BGTC with and without galactose, luciferase expression could neither be quantified in tumour or liver, nor in the spleen. Figure 2 presents the luciferase expression in tumour, liver and spleen after transfection with DNA MMS DOSP in the presence or absence of galactose and DNA LNCs with or without surface coating with $\mathrm{PEG}_{2000}$ compared to nontreated animals (control). DNA MMS DOSP showed no transfection efficiency as the levels of luciferase expression were similar to the control group. GAL DNA MMS DOSP demonstrated some luciferase expression in the tumour without any luciferase expression in the liver and spleen. On the other hand, DNA LNCs achieved low luciferase expression in the tumour, although there was some luciferase expression in the liver and spleen, whereas PEG DNA LNCs showed lower luciferase expression in the spleen and liver than DNA LNCs but higher luciferase expression in the tumour.

\section{Treatment efficacy of PEG DNA LNCs and GAL DNA MMS DOSP}

As a result of their tumour accumulation capacity, PEG DNA LNCs (group T1) and GAL DNA MMS DOSP (group T2) were selected and used in a GDEPT approach [4] consisting of the transfection of HSV-tk in tumour cells (Figure 3). This enzyme activates the prodrug GCV via phosphorylation, which in return will act as a chain terminator after incorporation into the DNA of dividing (tumour) cells $[4,5]$.

Five different control groups were analysed to assess the efficacy of these DNA nanocarriers: (i) no treatment (C1); (ii) GCV treatment alone (C2); (iii) PEG LNCs without DNA and without GCV treatment (C3); (iv) PEG DNA LNCs without GCV treatment (C4); and (v) GAL DNA MMS DOSP without GCV treatment (C5). PEG DNA LNCs were the most efficient vector using the GDEPT approach, with a significant tumour growth reduction in this group starting at day 2 ( $p=0.05$ for day 2 and 0.01 for the following days) and attaining $43 \%$ of tumour growth reduction at day 11 compared to the nontreated control group. GAL DNA MMS DOSP showed a lower treatment efficacy $(p=0.1$ for days 9, 10 and 11) but still attained 37\% of tumour growth reduction at day 11 compared to nontreated animals. Treatment of animals with GCV in the absence of any DNA nanocarrier also reduced tumour growth in a nonsignificant manner, as well as GAL DNA MMS DOSP without GCV treatment. By contrast, PEG DNA LNCs

Table 1. Specifications of the different DNA nanocarriers encapsulating the DNA plasmid pGWIZ-luciferase

\begin{tabular}{|c|c|c|c|c|c|c|}
\hline & \multicolumn{2}{|c|}{ Lipoplex composition } & \multicolumn{2}{|c|}{ Surface coating } & \multicolumn{2}{|c|}{ Physicochemical characteristics } \\
\hline & Cationic lipid & $\begin{array}{c}\text { Charge ratio } \\
(+/-)\end{array}$ & Polymer & $\begin{array}{l}\text { Polymer/DNA } \\
\text { ratio }(w / w)\end{array}$ & Size $(n m)$ & $\begin{array}{c}\text { Zeta potential } \\
(\mathrm{mV})\end{array}$ \\
\hline DNA LNC & DOTAP & 5 & - & - & $114 \pm 25$ & $27 \pm 12$ \\
\hline PEG DNA LNC & DOTAP & 5 & $\mathrm{PEG}_{2000}$ & 70 & $132 \pm 3$ & $-17 \pm 3$ \\
\hline DNA MMS BGTC & BGTC & 2 & F108 & 300 & $150 \pm 32$ & $-3 \pm 2$ \\
\hline GAL DNA MMS BGTC & BGTC & 2 & F108-galactose & 300 & $298 \pm 171$ & $-2 \pm 1$ \\
\hline DNA MMS DOSP & DOSP & 2 & F108 & 300 & $198 \pm 57$ & 0 \\
\hline GAL DNA MMS DOSP & DOSP & 2 & F108-galactose & 300 & $152 \pm 58$ & $-2 \pm 0$ \\
\hline
\end{tabular}




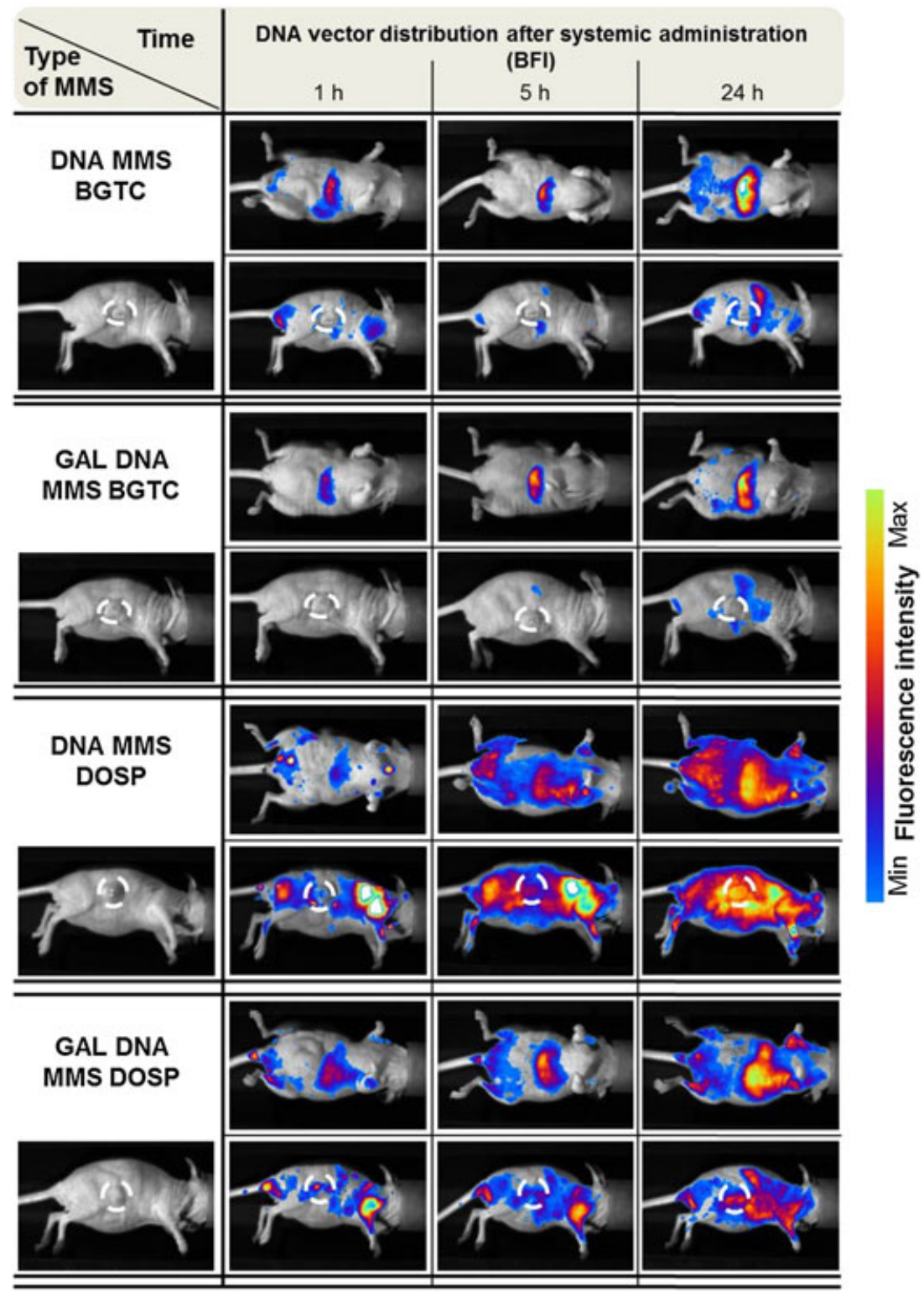

Figure 1. In vivo biofluorescence images of DNA MMS BGTC and DNA MMS DOSP with and without the ligand galactose at 1, 5 and $24 \mathrm{~h}$ after intravenous injection $(n=4)$. One mouse per group is represented, in both lateral and decubitus-dorsal views.

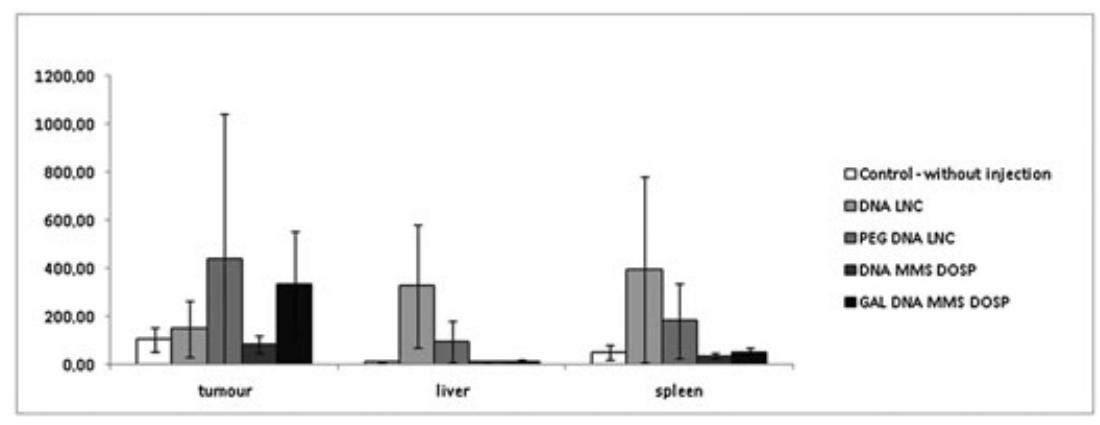

Figure 2. Quantification of luciferase expression in different organs (spleen and liver) and in the tumour $24 \mathrm{~h}$ after intravenous injection of different DNA nanocarriers (DNA LNCs, PEG DNA LNCs, DNA MMS DOSP with and without the ligand galactose and control mice without injections; $n=8$ for control mice and mice receiving DNA MMS and $n=6$ for DNA LNCs and PEG DNA LNCs).

without GCV treatment reduced the tumour growth to a level comparable to GAL DNA MMS DOSP. However, PEG LNCs without DNA and without GCV treatment did not reduce tumour growth, indicating that tumour growth reduction originates from the GCV and/or the DNA (in combination with the different nanocarriers). 


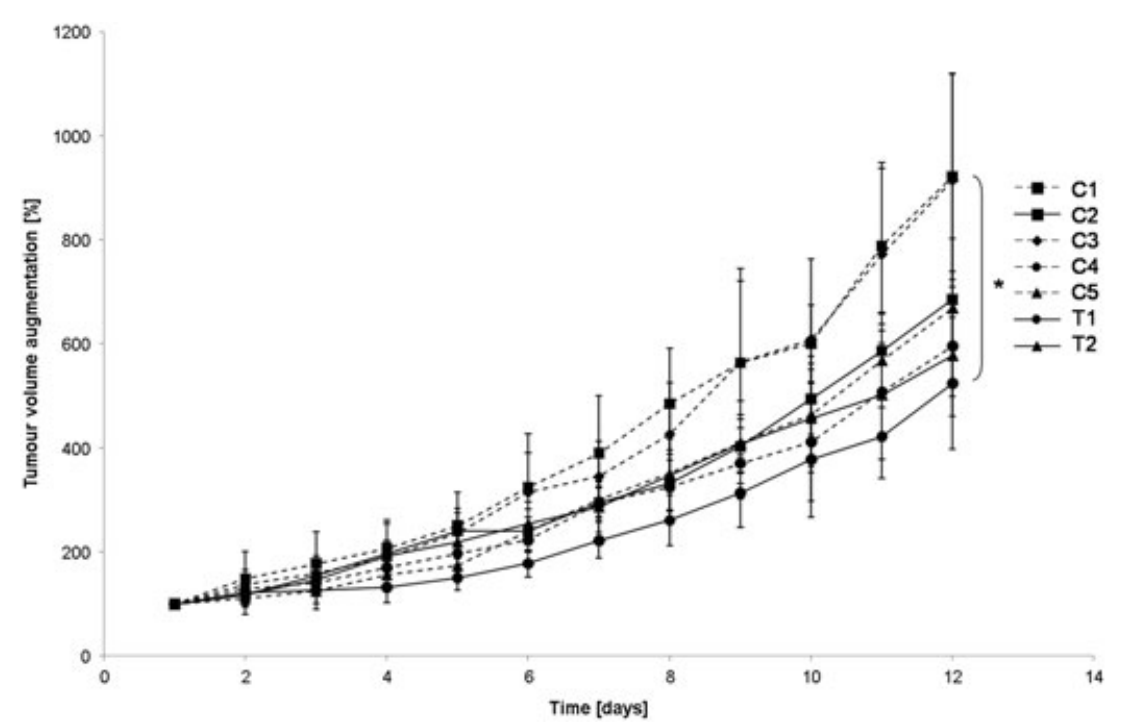

Figure 3. Treatment efficacy was determined by measuring the tumour volume once a day from the treatment day and during 11 days. It was represented by the augmentation of tumor volume as a percentage of tumor volume at day 0 [animals receiving no GCV dashed lines $(n=3)$, animals receiving GCV continuous lines ( $n=3$ for GCV treatment alone (C2) and $n=6$ for DNA nanocarrier administration (T1 and T2)), negative control (without injection) ((C1 and C2) squares, GAL DNA MMS DOSP triangles (C5 and T2)), PEG DNA LNCs circles ((C4 and T1), PEG LNCs without DNA (C3)) diamonds] *Statistically significant for C1 and T1 with $p=0.01$ starting at day 3.

\section{Discussion}

The recommended physicochemical properties for an 'ideal' nanocarrier administered via systemic injection are a size between 50 and $200 \mathrm{~nm}$, a neutral surface charge and the possibility to target a specific cell via active or passive targeting. In this respect, DNA LNCs were recovered by DSPE$\mathrm{PEG}_{2000}$ (PEG) to prolong the circulation time, which is necessary for passive targeting and to mask the positive surface charges as a result of the cationic lipid used for DNA complexation. DNA MMS already had neutral surface charges as a result of their composition and the ligand GAL was used for active targeting of asialoglycoproteinreceptors on hepatocytes. However, the addition of galactose on DNA MMS BGT augmented the size above $200 \mathrm{~nm}$. The physicochemical properties of these DNA nanocarriers indicate that compromises will have to be made to obtain efficient nanocarriers and further in vivo characterisation will determine the impact of these compromises.

As previously observed in healthy animals, the biodistribution profiles of our DNA nanocarriers varied with respect to the function of their lipid composition and their surface coating [17]. We observed the same tendency in this tumour model. On the one hand, the addition of galactose as a ligand accentuated the accumulation in the liver for both types of DNA MMS, certainly as a result of the active targeting via asialoglycoprotein receptors present on hepatocytes $[16,24,25]$ and also in the tumour region for the long circulating DNA MMS DOSP. The presence of the ligand galactose appears to be important for promoting the transfection efficiency of these DNA MMS because DNA MMS DOSP did not show any luciferase expression, although tumour accumulation was observed via in vivo BFI. This could probably be explained because lectins, such as galectin-1 [26], a galactose-specific lectin correlating with the grade of malignancy, are highly expressed in human gliomas [27,28], allowing active targeting. On the other hand, the surface coating with long DSPE-PEG chains also appears to promote transfection efficiency in the tumour because luciferase expression of PEG DNA LNCs in the tumour was more important than for DNA LNCs. This accumulation and expression of PEG DNA LNCs in the tumour region is certainly a result of the passive targeting mechanism linked to the enhanced permeability and retention (EPR) effect, which is well documented in the literature $[29,30]$. This EPR effect is a result of the 'leaky', tortuous and heterogeneous tumour vessels, with pore sizes between $100 \mathrm{~nm}$ and almost $1 \mu \mathrm{m}$, depending on the anatomic tumour location and tumour growth [12], which results in the enhanced retention of particles such as stealth nanocarriers.

The results obtained in the present study for the treatment experiment using the GDEPT approach are in good agreement with the results obtained via in vivo BFI and luciferase quantification analysis and are also in accordance with previous results obtained on a melanoma mouse model where treatment efficacy compared to nontreated mice was shown at day 4 after LNC administration [15]. The use of PEG DNA LNCs with a HSV-tk-coding plasmid and subsequent GCV treatment significantly reduced the tumour growth compared to nontreated animals. The nanocarrier GAL DNA MMS DOSP also reduced tumour growth but to a lesser extent. To circumvent this, a repeated administration could be envisaged in the future. An important bystander effect was described in the literature using this approach on glioma cells, allowing the reduction of HSV-tk/GCV doses because, in certain cases, only $10 \%$ of the tumour cells have to be transfected [31-33].

The cytotoxic effect of GCV alone was also observed in the literature, especially at higher doses [34-36]. As a result of the heterogeneous tumour growth in this glioma model, more animals in each group and an earlier start of 
treatment could probably improve the difference in Acknowledgements

tumour growth between treatment and control groups.

In conclusion, the present study investigated the biodistribution, transfection and treatment efficacy of new DNA nanocarriers in an ectopic glioma mouse model after systemic administration. The results obtained highlight the potential use of PEG DNA LNCs and GAL DNA MMS DOSP as future therapeutics in glioma or other cancers.

The authors would like to thank Pierre Legras (SCAHU, Angers) for his help in the design of the in vivo experiments, as well as his technical help. This work was supported by special grants from the "Région Pays de la Loire" (CIMATH), "Biogenouest", "Région Bretagne", "Ligue contre le cancer 29" and the "Canceropole Grand Ouest". The authors declare that there are no conflicts of interest.

\section{References}

1. Arko L, Katsyv I, Park GE, Luan WP, Park JK. Experimental approaches for the treatment of malignant gliomas. Pharmacol Ther 2010; 128: 1-36.

2. Allard E, Passirani C, Benoit JP. Convectionenhanced delivery of nanocarriers for the treatment of brain tumours. Biomaterials 2009; 30: 2302-2318.

3. Stupp R, Hegi ME, Mason WP, et al. Effects of radiotherapy with concomitant and adjuvant temozolomide versus radiotherapy alone on survival in glioblastoma in a randomized phase III study: 5-year analysis of the EORTC-NCIC trial. Lancet Oncol 2009; 10: 459-466.

4. Portsmouth D, Hlavaty J, Renner M. Suicide genes for cancer therapy. $\mathrm{Mol}$ Aspects Med 2007; 28: 4-41.

5. Altaner C. Prodrug cancer gene therapy. Cancer Lett 2008; 270: 191-201.

6. Immonen A, Vapalahti M, Tyynela K, et al. AdvHSV-tk gene therapy with intravenous ganciclovir improves survival in human malignant glioma: a randomized, controlled study. Mol Ther 2004; 10: 967-972.

7. Chowdhury EH. Nuclear targeting of viral and non-viral DNA. Expert Opin Drug Deliv 2009; 6: 697-703.

8. Collins SA, Guinn BA, Harrison PT, Scallan MF, O'Sullivan GC, Tangney M. Viral vectors in cancer immunotherapy: which vector for which strategy? Curr Gene Ther 2008; 8: 66-78.

9. Jin S, Ye K. Nanoparticle-mediated drug delivery and gene therapy. Biotechnol Prog 2007; 23: 32-41.

10. Kreiss P, Cameron B, Rangara R, et al. Plasmid DNA size does not affect the physicochemical properties of lipoplexes but modulates gene transfer efficiency. Nucleic Acids Res 1999; 27: 3792-3798.

11. Morille M, Passirani C, Vonarbourg A, Clavreul A, Benoit JP. Progress in developing cationic vectors for non-viral systemic gene therapy against cancer. Biomaterials 2008; 29: 3477-3496.

12. Huynh NT, Roger E, Lautram N, Benoit JP, Passirani C. The rise and rise of stealth nanocarriers for cancer therapy: passive versus active targeting. Nanomedicine (Lond) 2010; 5: 1415-1433.

13. Vonarbourg A, Passirani C, Desigaux L, et al. The encapsulation of DNA molecules within biomimetic lipid nanocapsules. Biomaterials 2009; 30: 3197-3204.

14. Morille M, Passirani C, Dufort S, et al. Tumour transfection after systemic injection of DNA lipid nanocapsules. Biomaterials 2011; 32: 2327-2333.

15. David S, Carmoy N, Resnier P, et al. In vivo imaging of DNA lipid nanocapsules after systemic administration in a melanoma mouse model. Int $J$ Pharm 2012; 423: 108-115.

16. Letrou-Bonneval E, Chevre R, Lambert $\mathrm{O}$, et al. Galactosylated multimodular lipoplexes for specific gene transfer into primary hepatocytes. J Gene Med 2008 10: 1198-1209.

17. David S, Passirani C, Carmoy N, et al. DNA nanocarriers for systemic administration - characterization and in vivo bioimaging in healthy mice. Mol Ther NA. DOI: $10.1038 / \mathrm{mtna} .2012 .56$

18. Billiet L, Gomez JP, Berchel M, et al. Gene transfer by chemical vectors, and endocytosis routes of polyplexes, lipoplexes and lipopolyplexes in a myoblast cell line. Biomaterials 2012; 33: 2980-2990.

19. Desigaux L, Sainlos M, Lambert O, et al. Self-assembled lamellar complexes of siRNA with lipidic aminoglycoside derivatives promote efficient siRNA delivery and interference. Proc Natl Acad Sci USA 2007; 104: 16534-16539.

20. Vigneron JP, Oudrhiri N, Fauquet $M$, et al. Guanidinium-cholesterol cationic lipids: efficient vectors for the transfection of eukaryotic cells. Proc Natl Acad Sci USA 1996; 93: 9682-9686.

21. Garcion E, Lamprecht A, Heurtault B, et al. A new generation of anticancer, drugloaded, colloidal vectors reverses multidrug resistance in glioma and reduces tumour progression in rats. Mol Cancer Ther 2006; 5: 1710-1722.

22. Heurtault B, Saulnier P, Pech B, Proust JE, Benoit JP. A novel phase inversion-based process for the preparation of lipid nanocarriers. Pharm Res 2002; 19: 875-880.

23. Morille $\mathrm{M}$, Montier $\mathrm{T}$, Legras $\mathrm{P}$, et al. Long-circulating DNA lipid nanocapsules as new vector for passive tumour targeting. Biomaterials 2009; 31: 321-329.

24. Schwartz AL. The hepatic asialoglycoprotein receptor. CRC Crit Rev Biochem 1984; 16: 207-233.

25. Steirer LM, Park EI, Townsend RR, Baenziger JU. The asialoglycoprotein receptor regulates levels of plasma glycoproteins terminating with sialic acid alpha2,6-galactose. $J$ Biol Chem 2009; 284: 3777-3783.

26. Camby I, Le Mercier M, Lefranc F, Kiss R. Galectin-1: a small protein with major functions. Glycobiology 2006; 16: 137R-157R.

27. Rorive S, Belot N, Decaestecker C, et al. Galectin-1 is highly expressed in human gliomas with relevance for modulation of invasion of tumour astrocytes into the brain parenchyma. Glia 2001; 33: 241-255.

28. Camby I, Decaestecker C, Lefranc F, Kaltner H, Gabius HJ, Kiss R. Galectin-1 knocking down in human U87 glioblastoma cells alters their gene expression pattern. Biochem Biophys Res Commun 2005; 335: 27-35.

29. Maeda H, Wu J, Sawa T, Matsumura Y, Hori K. Tumour vascular permeability and the EPR effect in macromolecular therapeutics: a review. $J$ Control Release 2000; 65: 271-284.

30. Maeda $H$. The enhanced permeability and retention (EPR) effect in tumour vasculature: the key role of tumourselective macromolecular drug targeting. Adv Enzyme Regul 2001; 41: 189-207.

31. Maatta AM, Samaranayake H, Pikkarainen J, Wirth T, Yla-Herttuala S. Adenovirus mediated herpes simplex virus-thymidine kinase/ganciclovir gene therapy for resectable malignant glioma. Curr Gene Ther 2009; 9: 356-367.

32. Matuskova M, Hlubinova K, Pastorakova A, et al. HSV-tk expressing mesenchymal stem cells exert bystander effect on human glioblastoma cells. Cancer Lett 2009; 290: 58-67.

33. Culver KW, Ram Z, Wallbridge S, Ishii $\mathrm{H}$, Oldfield EH, Blaese RM. In vivo gene transfer with retroviral vector-producer cells for treatment of experimental brain tumours. Science 1992; 256: 1550-1552.

34. Nanda D, Vogels R, Havenga M, Avezaat CJ, Bout A, Smitt PS. Treatment of malignant gliomas with a replicating adenoviral vector expressing herpes simplex virus-thymidine kinase. Cancer Res 2001; 61: 8743-8750.

35. Soubrane C, Mouawad R, Rixe O, et al. Direct gene transfer of a plasmid carrying the herpes simplex virus-thymidine kinase gene (HSV-TK) in transplanted murine melanoma: in vivo study. Eur $J$ Cancer 1996; 32A: 691-695.

36. Rosolen A, Frascella E, di Francesco C, et al. In vitro and in vivo antitumour effects of retrovirus-mediated herpes simplex thymidine kinase gene-transfer in human medulloblastoma. Gene Ther 1998; 5: 113-120. 